\title{
Case Report: Buccal administration of hydrogen-producing \\ blend after a mild traumatic brain injury in a professional
}

\section{athlete [version 1; peer review: 2 approved]}

\author{
Dejan Javorac¹, Valdemar Stajer ${ }^{1}$, Sergej M. Ostojic (iD)1,2 \\ ${ }^{1}$ Faculty of Sport and Physical Education, University of Novi Sad, Novi Sad, 21000, Serbia \\ ${ }^{2}$ Faculty of Health Sciences, University of Pecs, Pecs, H-7621, Hungary
}

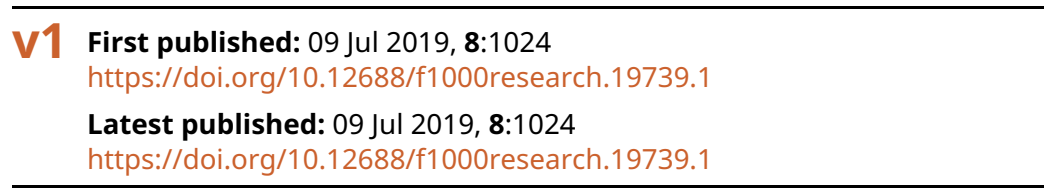

\section{Abstract}

Background: Sport-related mild traumatic brain injury (TBI) is a serious trauma that could impair brain function of an injured athlete. Treatment solutions for mild TBI typically concentrate on complete rest, while non-traditional therapeutic options remain largely ineffective. Molecular hydrogen $\left(\mathrm{H}^{2}\right)$ is an innovative neuroprotective agent that can easily reach the brain, yet no data are available concerning its value as a first-aid intervention after a mild TBI.

Case report: This case report demonstrates the efficacy and safety of a hydrogen-producing dissolving tablet administered buccally during the first 24 hours post-injury in a professional soccer player who suffered a mild TBI. The patient received a formulated dosage of hydrogen every 2 hours, with the first intervention given immediately after an initial examination ( 15 min after the injury).

The overall score for Sport Concussion Assessment Tool 2 (SCAT2), a standardized method of evaluating injured athletes for concussion, increased from 68 points (severe disruption) at baseline to 84 points (mild disruption) at 24-h follow-up. The patient reported no side effects of hydrogen intervention.

Conclusions: This case has demonstrated that intensive consecutive therapy with oral transmucosal hydrogen formulation is a beneficial strategy with regard to the reduction of presence and severity of symptoms of sport-related mild TBI.

\section{Keywords}

Traumatic brain injury, Concussion, Hydrogen, Recovery, Buccal administration, Athlete

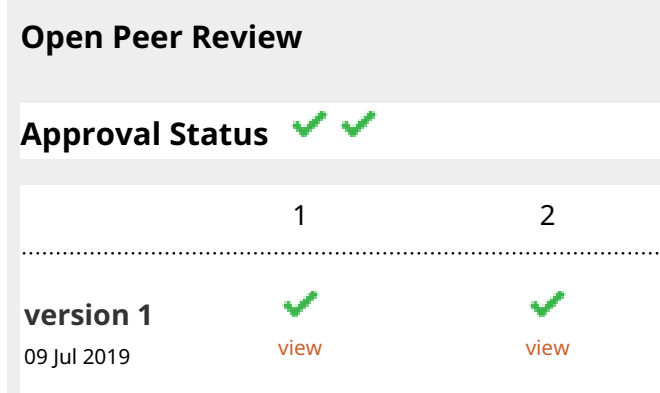

1. Cheong Hwa Ooi iD, Universiti Sains

Malaysia, Kepala Batas, Malaysia

2. Shohei Dobashi, Juntendo University, Inzai, Japan

Katsuhiro Koyama, University of Yamanashi, Yamanashi, Japan

Any reports and responses or comments on the article can be found at the end of the article. 
Corresponding author: Sergej M. Ostojic (sergej.ostojic@chess.edu.rs)

Author roles: Javorac D: Formal Analysis, Investigation, Methodology, Visualization, Writing - Review \& Editing; Stajer V: Formal Analysis, Investigation, Methodology, Visualization, Writing - Review \& Editing; Ostojic SM: Conceptualization, Data Curation, Funding Acquisition, Project Administration, Resources, Supervision, Writing - Original Draft Preparation

Competing interests: No competing interests were disclosed.

Grant information: his study is supported by the Serbian Ministry of Education, Science and Technological Development (\#175037); the Provincial Secretariat for Higher Education and Scientific Research (\#114-451-710); and the Center for Health, Exercise and Sport Sciences, Belgrade.

The funders had no role in study design, data collection and analysis, decision to publish, or preparation of the manuscript.

Copyright: @ 2019 Javorac $D$ et al. This is an open access article distributed under the terms of the Creative Commons Attribution License, which permits unrestricted use, distribution, and reproduction in any medium, provided the original work is properly cited.

How to cite this article: Javorac D, Stajer V and Ostojic SM. Case Report: Buccal administration of hydrogen-producing blend after a mild traumatic brain injury in a professional athlete [version 1; peer review: 2 approved] F1000Research 2019, 8:1024

https://doi.org/10.12688/f1000research.19739.1

First published: 09 Jul 2019, 8:1024 https://doi.org/10.12688/f1000research.19739.1 


\section{Introduction}

Sport-related concussion or mild traumatic brain injury (TBI) is a perilous trauma that could impair the brain function of an injured athlete both acutely and in a long-term perspective. Up to 3.8 million sport-related concussions occur in the United States annually, with contact sports (e.g. football, wrestling, soccer, boxing, basketball, ice hockey) accounting for the greatest number of concussions ${ }^{2}$. Common signs and symptoms of acute mild TBI include physical (e.g. headache, dizziness, nausea, vomiting, fatigue), cognitive (e.g. loss of consciousness, post-traumatic amnesia, difficulties with concentration and memory), emotional (e.g. irritability, depressed mood) and sleep-related problems (e.g. drowsiness, sleeping disturbances) ${ }^{3}$. This happens probably due to a complex cascade of neurometabolic alterations in brain neurons damaged by head accelerationdeceleration mechanical forces ${ }^{4}$, with mitochondrial dysfunction, energy metabolism disturbances, and excessive oxidative stress might play a role ${ }^{5}$. Treatment solutions for sport-related concussion typically focus on complete rest at first (including a temporary withdrawal from practice and mental activities) followed by slow return-to-play activities monitored and clearance by a physician ${ }^{3}$. Non-traditional therapies, such as dietary supplements, enteral nutrition, acupuncture, and music therapy, are being considered to combat mild TBI, yet the therapeutic options remain limited ${ }^{6}$. Molecular hydrogen $\left(\mathrm{H}_{2}\right)$ has recently been set forth as an innovative neuroprotective agent ${ }^{7}$ that can easily reach hard-to-reach biocompartments ${ }^{8}$, yet no data are available concerning its value as a first-aid intervention in mild TBI. This case report demonstrates the efficacy and safety of a hydrogen-producing blend administered buccally in a professional athlete that suffered a sport-related concussion.

\section{Case report}

\section{Patient information}

An apparently healthy young male professional soccer player (age 24 years, weight $75.1 \mathrm{~kg}$, height $182.5 \mathrm{~cm}$, professional experience 6 years) who suffered a sport-related concussion voluntarily participated in this case study. The injury occurred during a regular training session as a head-to-head collision with another player. There was a loss of consciousness for $\sim 30 \mathrm{sec}$ and the patient was immediately evaluated by a health care professional who confirmed the category of an injury by a physical examination. The patient had no history of concussion or other TBI in the past 6 months and no neurological, psychiatric or other chronic conditions. Written informed consent to be treated was obtained from the patient in accordance with the Declaration of Helsinki. Treatment using therapeutic hydrogen of athletes who experience a TBI was approved by the FSPE Applied Bioenergentics Lab (University of Novi Sad, Serbia; approval number, HBCS02-2019).

\section{Clinical findings}

At the initial examination, the patient was profiled using Sport Concussion Assessment Tool 2 (SCAT2), a standardized method of evaluating injured athletes for concussion'. The total number of concussion symptoms was 18 (out of maximal 22), with a symptom severity score of 53 (out of 132).
Glasgow Coma Scale (GCS) score at baseline was 13 out of 15, corresponding to mild closed head injury. Total SCAT2 score was 68 out of 100 points, approximately $25.3 \%$ below normative values $(91.08)^{10}$. In addition, the patient has shown a diminished ability to keep balance during a single-leg stance test (SLST) for non-dominant foot (total number of errors 5 out of 10).

\section{Therapeutic intervention}

A hydrogen-producing blend was administered buccally during the first 24 hours post-injury. Hydrogen was used as an exclusive treatment (along with physical and mental rest) with the main aim to reduce symptoms and signs of concussion, and it was anticipated to accelerate the acute recovery. The patient received a formulated 700-mg tablet (producing $\sim 80 \mathrm{~mL}$ of $\mathrm{H}_{2}$ ) every 2 hours throughout the monitoring period, with the first intervention given immediately after an initial examination ( 15 min after the injury). The patient was requested to put a tablet into the mouth, preferentially between the gums and teeth, and keep it inside until full dissolution. A small quantity of tap water ( $~ 50 \mathrm{~mL})$ has been provided for mouth rinsing to improve breaking up the tablet during each administration. Buccal administration was applied due to anticipated better bioavailability, more rapid onset of action, and decreased possible risk of vomiting, a well-known manifestation of concussion. The intervention was freely provided by HRW Natural Health Products Inc. (Drink HRW Rejuvenation, New Westminster, BC, Canada).

\section{Follow-up and outcomes}

SCAT2 profiles were obtained at every 6 hours during the first 24 hours post-injury (Figure 1). Total SCAT2 scores have risen from 68 (initial score) to 72 points at first re-evaluation period and continued to increase to 84 points at the final follow-up examination. In addition, the total number of concussion symptoms decreased to 9 at 24-h follow-up, with symptom severity score dropping to 12 (out of 132), while SLST balance test improved by $25 \%$ (total number of errors 2 out of 10 at 24$\mathrm{h}$ follow-up). The patient reported no side effects of hydrogen intervention, as evaluated with an open-ended questionnaire administered at the end of each treatment period; the patient was asked if the intervention resulted in any adverse events, including oral irritation or discomfort, tingling in the mouth, dizziness, nausea or flushing.

\section{Discussion}

This case report implies the favorable effects of hydrogenproducing dissolving tablet administered buccally as a possible first-aid treatment to improve recovery in a professional athlete with a mild TBI. Previous animal studies have demonstrated neuroprotective effects of hydrogen against perinatal ${ }^{11}$ and ischemic brain injury ${ }^{12}$, or brain damage induced by neurosurgical intervention ${ }^{13}$. In a recent pivotal study ${ }^{14}$, TBI-challenged rats exhibited significant brain injuries that were characterized by decreased survival rate and increased blood-brain barrier permeability, brain edema, and neurological dysfunction, while hydrogen treatment ameliorated the consequences of TBI. The authors concluded that hydrogen could exert a neuroprotective 


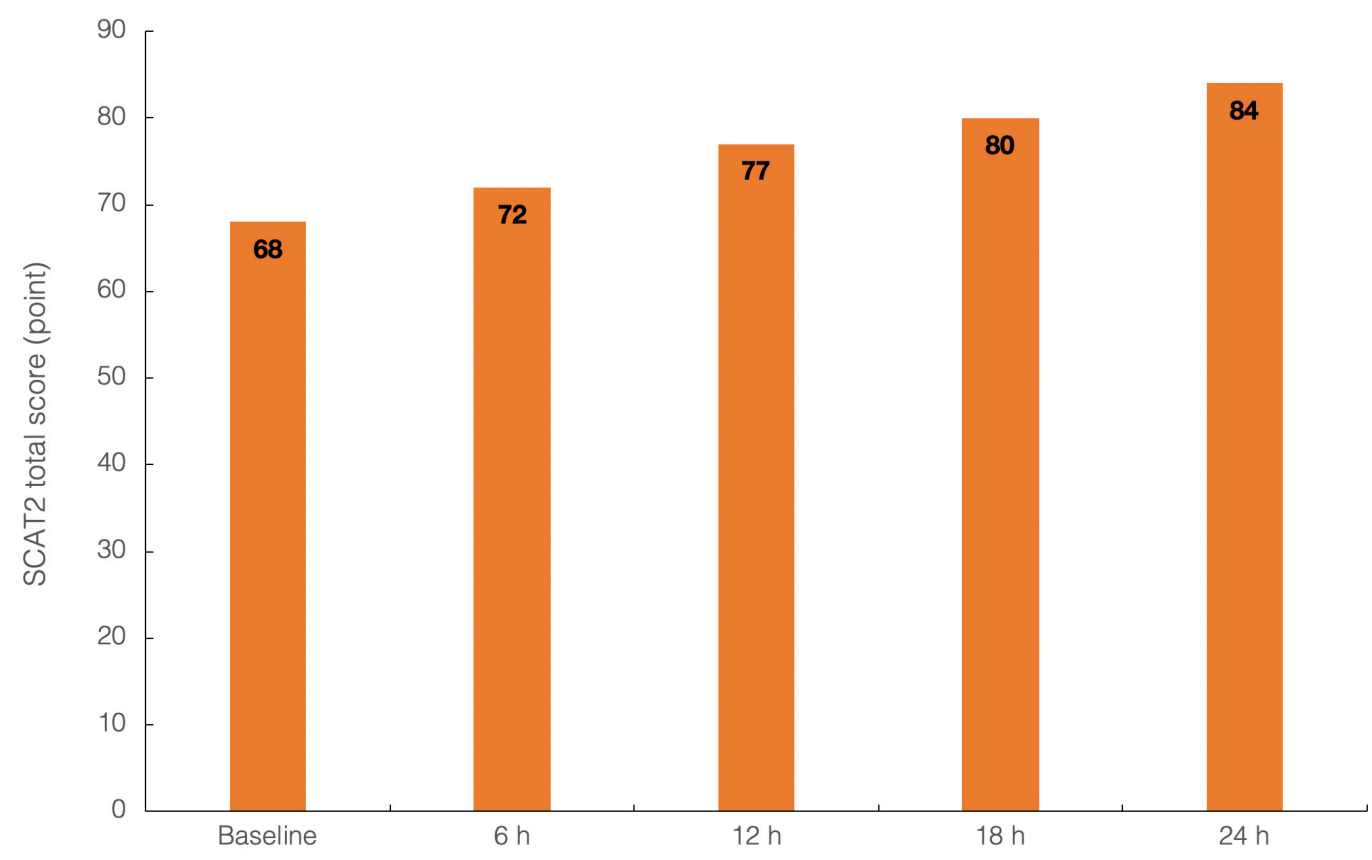

Figure 1. Sport Concussion Assessment Tool 2 (SCAT2) total scores at baseline and at each 6-h follow-up interval.

effect against TBI and attenuate inflammation and/or oxidative stress $^{14}$, which put forward the intervention as a possible therapeutic strategy for TBI patients. Using an innovative route of administration and a benchmark tool (SCAT2) to evaluate injured athletes for concussion, we affirmed here that oral hydrogen ameliorates the presence and severity of symptoms of sport-related mild TBI. However, hydrogen has not been compared to placebo so the degree of advantage that hydrogen may provide to standard medical procedures for concussion (e.g. physical and mental rest) remains open to question. We strongly suggest further monitoring of the efficacy and safety of oral transmucosal hydrogen in sport-related mild TBIs on a larger similar case series using randomized controlled trials.

\section{Consent}

Written informed consent was obtained from the patient for the publication of this case report, including any associated images.

\section{Data availability}

All data underlying the results are available as part of the article. No additional source data are required.

\section{Grant information}

This study is supported by the Serbian Ministry of Education, Science and Technological Development (\#175037); the Provincial Secretariat for Higher Education and Scientific Research (\#114-451-710); and the Center for Health, Exercise and Sport Sciences, Belgrade.

The funders had no role in study design, data collection and analysis, decision to publish, or preparation of the manuscript.

\section{Acknowledgments}

The authors wish to thank Miss Nastassya Ostojic for SCAT2 data pre-processing.
1. Langlois JA, Rutland-Brown W, Wald MM: The epidemiology and impact of traumatic brain injury: a brief overview. J Head Trauma Rehabil. 2006; 21(5): 375-378.

PubMed Abstract | Publisher Full Text

2. Marar M, Mcllvain NM, Fields SK, et al.: Epidemiology of concussions among United States high school athletes in 20 sports. Am J Sports Med. 2012; 40(4): 747-755.

PubMed Abstract | Publisher Full Text
3. Clark M, Guskiewicz K: Sport-Related Traumatic Brain Injury. In: Laskowitz D, Grant G, editors. Translational Research in Traumatic Brain Injury. Boca Raton (FL): CRC Press/Taylor and Francis Group; 2016. Chapter 2. PubMed Abstract

4. Steenerson K, Starling AJ: Pathophysiology of Sports-Related Concussion. Neurol Clin. 2017; 35(3): 403-408. PubMed Abstract | Publisher Full Text

5. Signoretti S, Lazzarino G, Tavazzi B, et al:: The pathophysiology of concussion. 
PM R. 2011; 3(10 Suppl 2): S359-368.

PubMed Abstract | Publisher Full Text

6. Lucke-Wold BP, Logsdon AF, Nguyen L, et al:: Supplements, nutrition, and alternative therapies for the treatment of traumatic brain injury. Nutr Neurosci. 2018; 21(2): 79-91.

PubMed Abstract | Publisher Full Text | Free Full Text

7. Iketani M, Ohsawa I: Molecular Hydrogen as a Neuroprotective Agent. Cur Neuropharmacol. 2017; 15(2): 324-331.

PubMed Abstract | Publisher Full Text | Free Full Text

8. Ostojic SM: Targeting molecular hydrogen to mitochondria: barriers and gateways. Pharmacol Res. 2015; 94: 51-53.

PubMed Abstract | Publisher Full Text

9. Rădoi A, Poca MA, Gándara D, et al.: The Sport Concussion Assessment Too (SCAT2) for evaluating civilian mild traumatic brain injury. A pilot normative study. PLOS One. 2019; 14(2): e0212541.

PubMed Abstract | Publisher Full Text | Free Full Text

10. Zimmer A, Marcinak J, Hibyan S, et al:: Normative values of major SCAT2 and
SCAT3 components for a college athlete population. Appl Neuropsychol Adult. 2015; 22(2): 132-140.

PubMed Abstract | Publisher Full Text

11. Imai K, Kotani T, Tsuda H, et al:: Neuroprotective potential of molecular hydrogen against perinatal brain injury via suppression of activated microglia. Free Radic Biol Med. 2016; 91: 154-163. PubMed Abstract | Publisher Full Text

12. Nagasaki G, Masaki Y, Horiguchi T, et al:: Neuroprotective effect of hydrogen gas on brain injury in a rat transient forebrain ischemia model. Anesth Analg. 2016; 123(3S): 199. Publisher Full Text

13. Eckermann JM, Chen W, Jadhav V, et al:: Hydrogen is neuroprotective against surgically induced brain injury. Med Gas Res. 2011; 1(1): 7. PubMed Abstract | Publisher Full Text | Free Full Text

14. Tian R, Hou Z, Hao S, et al:: Hydrogen-rich water attenuates brain damage and inflammation after traumatic brain injury in rats. Brain Res. 2016; 1637: 1-13. PubMed Abstract | Publisher Full Text 


\section{Open Peer Review}

\section{Current Peer Review Status:}

\section{Version 1}

Reviewer Report 16 June 2020

https://doi.org/10.5256/f1000research.21648.r64103

(C) 2020 Koyama $\mathbf{K}$ et al. This is an open access peer review report distributed under the terms of the Creative Commons Attribution License, which permits unrestricted use, distribution, and reproduction in any medium, provided the original work is properly cited.

\section{Shohei Dobashi}

Institute of Health and Sports Science \& Medicine, Juntendo University, Inzai, Chiba, Japan

\section{Katsuhiro Koyama}

Graduate School Department of Interdisciplinary Research, University of Yamanashi, Yamanashi, Japan

Sports-related mild traumatic brain injury (TBI) is one of social issues to solve in modern society, because the sports-related TBI increases subsequent mortality from neurodegenerative disorders, such as dementia. Given that if molecular hydrogen might easily reach injured brain area and induce some cytoprotective effects as the authors mentioned in this report, we evaluate the firstaid intervention by hydrogen administration as novel and innovative approach on the sportsrelated TBI.

In order to potentiate the view that molecular hydrogen is beneficial for acute phase of sportsrelated TBI, we would like to propose the authors to consider some additional concerns as written below.

Because of a case report, we understand that this study did not set placebo control trial (i.e., physical and mental rest without hydrogen treatment). However, we believe that the representation of the typical time course change in SCAT2 score without any specific medication will strongly enhance the therapeutic value of this intervention.

Another point is that SCAT2 consists several clusters of assessment items (e.g., somatic, cognitive, emotional, and sleep-fatigue symptoms), nevertheless the authors displayed just only total SCAT2 score in this study. The information about which individual factor was improved by hydrogen treatment is so important to assess its efficacy and examine the target of the treatment. Thus, we would like to propose the authors to display the time course changes not only total score but also each score of SCAT2 symptoms.

\section{References}

1. Mackay D, Russell E, Stewart K, MacLean J, et al.: Neurodegenerative Disease Mortality among Former Professional Soccer Players. New England Journal of Medicine. 2019; 381 (19): 1801-1808

Publisher Full Text 
2. Rădoi A, Poca MA, Gándara D, Castro L, et al.: The Sport Concussion Assessment Tool (SCAT2) for evaluating civilian mild traumatic brain injury. A pilot normative study.PLoS One. 2019; 14 (2): e0212541 PubMed Abstract | Publisher Full Text

Is the background of the case's history and progression described in sufficient detail? Yes

Are enough details provided of any physical examination and diagnostic tests, treatment given and outcomes?

Yes

Is sufficient discussion included of the importance of the findings and their relevance to future understanding of disease processes, diagnosis or treatment?

Yes

Is the case presented with sufficient detail to be useful for other practitioners? Yes

Competing Interests: No competing interests were disclosed.

Reviewer Expertise: Exercise; Oxidative stress; Hypoxia; Molecular hydrogen; Sport-related concussion;

We confirm that we have read this submission and believe that we have an appropriate level of expertise to confirm that it is of an acceptable scientific standard.

Reviewer Report 29 November 2019

https://doi.org/10.5256/f1000research.21648.r56420

(C) 2019 Ooi C. This is an open access peer review report distributed under the terms of the Creative Commons Attribution License, which permits unrestricted use, distribution, and reproduction in any medium, provided the original work is properly cited.

\section{Cheong Hwa Ooi}

Advanced Medical And Dental Institute, Universiti Sains Malaysia, Kepala Batas, Malaysia

Apart from physical and mental rest, there are limited options for clinical management of sportrelated concussions or mild traumatic brain injury (TBI). This case report suggests that the ingestion of hydrogen-producing tablets may be a viable treatment to improve the recovery of the concussed footballer.

The neuroprotective effects of molecular hydrogen against TBI have been demonstrated in animal models, in the form of hydrogen gas inhalation or hydrogen-rich water administration. However, its efficacy in treating mild TBI in humans has not been examined. The buccal administration of the molecular hydrogen in the present case report represents an innovative 
immediate treatment approach to manage TBI in the field.

The favorable outcomes of the intervention highlight the importance of a more extensive case series, and subsequently the need to conduct controlled trials in examining the therapeutic effects of molecular hydrogen on signs and symptoms of acute mild TBI in athletes.

Is the background of the case's history and progression described in sufficient detail? Yes

Are enough details provided of any physical examination and diagnostic tests, treatment given and outcomes?

Yes

Is sufficient discussion included of the importance of the findings and their relevance to future understanding of disease processes, diagnosis or treatment?

Yes

Is the case presented with sufficient detail to be useful for other practitioners?

Yes

Competing Interests: No competing interests were disclosed.

Reviewer Expertise: Heat Shock Proteins and Health; Eccentric Exercise-induced Muscle Damage; Molecular Hydrogen and Exercise Performance

I confirm that I have read this submission and believe that I have an appropriate level of expertise to confirm that it is of an acceptable scientific standard.

The benefits of publishing with F1000Research:

- Your article is published within days, with no editorial bias

- You can publish traditional articles, null/negative results, case reports, data notes and more

- The peer review process is transparent and collaborative

- Your article is indexed in PubMed after passing peer review

- Dedicated customer support at every stage

For pre-submission enquiries, contact research@f1000.com

F1000Research 